\title{
São Paulo: além do Plano Diretor
}

\author{
MARIA LUCIA REFINETTI MARTINS
}

A REGIÃo M etropolitana São Paulo concentra 10,5\% da população brasileira, (mais de $5 \%$ se considerado só o município de São Paulo), responde por aproximadamente $18 \%$ do PIB $^{1}$, apresenta um desemprego da ordem de $17,6 \%{ }^{2}$, um déficit habitacional equivalente a quase $12 \%^{3} \mathrm{e}$, em parcelas de seu território, os mais altos índices de violência no país. 0 que se passa aqui é muito significativo, não só em relação ao cômputo geral de indicadores e na totalização de dados no país, mas também por ressaltar algumas das relações existentes entre cidade e desenvolvimento. 0 presente texto se propõe a analisar a constituição da política urbana em São Paulo, situando-a no contexto dos debates ora em curso (Plano Diretor, Conselhos, Subprefeituras), das inovações legais e do desenvolvimento do país.

A cidade acumula situações de exclusão econômica e territorial e as torna mais evidentes, especialmente quando as coloca ao lado de ícones da modernidade e do atual modelo de globalização. Para abranger a dimensão dessa exclusão se faz necessário olhar a cidade sob dois pontos de vista: o da esfera visível, em que se inserem as ações diretas do poder público: produção de habitação, saneamento, transportes; e o da esfera invisível - das transferências de renda que a própria estrutura urbana engendra.

À parte as demandas mais evidentes - como escolas, postos de saúde, pavimentação, expressas como reivindicação ou apresentadas como orçamento participativo - pouco se conhece do impacto de políticas urbanas sobre a sociedade e sobre a economia. Se a alíquota do ICM S sobre o frango ou sobre os eletrodomésticos, por exemplo, muda, cedo se percebe o impacto no consumo. D e certo modo, o mesmo ocorre no transporte público quando ocorre elevação de tarifa. $M$ as, se a freqüência desse mesmo transporte é reduzida, seus efeitos são de muito mais difícil percepção. D o mesmo modo, se uma operação imobiliária desloca o "centro" de atividades em determinada direção, é difícil expressar o que a região ou o restante da cidade teve de benefícios ou de perdas.

N esses termos, o propósito do texto é discutir a relação entre política urbana (inclusive o Plano D iretor), inclusão social e desenvolvimento, e a contribuição que a U niversidade, em sua especificidade de formação e de produção de conhecimento pode oferecer para a compreensão e o enfrentamento do tema.

A hipótese é de que a ação dos M unicípios, na esfera de sua competência e da natureza própria da cidade, tem um imenso potencial capaz de favorecer ou 
de restringir processos de inclusão social, promovendo ou comprometendo a necessária modernização da sociedade brasileira. Além disso, a específica competência municipal de "planejamento e controle do uso, do parcelamento e da ocupação do solo urbano", tem implicações não somente territoriais, mas reflexos também na economia e na sociedade.

\section{0 quadro institucional da cidade no Brasil}

U ma das primeiras medidas do Presidente Luiz I nácio Lula da Silva, logo após sua posse, foi a criação do M inistério das Cidades. Seu significado é da maior importância para a política urbana brasileira, pois eleva as cidades a um novo patamar, já apontado com a aprovação do Estatuto da Cidade (10.257/ 2001), que atribui às cidades brasileiras um novo estatuto.

O M unicípio de São Paulo, porção central da Região M etropolitana com 39 municípios, depara-se, além dos temas do Estatuto da Cidade, com aspectos supra e submunicipais. Entre os primeiros, estão pautas metropolitanas como 0 transporte público, o rodoanel e a gestão dos recursos hídricos, particularmente a captação de água potável e a política em relação ao esgoto. Localmente, há o debate quanto aos Planos Regionais de Subprefeituras que, juntamente com 0 Plano de Transportes e 0 de $\mathrm{H}$ abitação deverão ser apresentados ao L egislativo até o final de abril de 2003, para incorporarem-se ao Plano D iretor Estratégico, aprovado e sancionado no final de 2001. Também estão em pauta as eleições para o Conselho M unicipal de H abitação (durante março de 2003), e a constituição do C onselho M unicipal de D esenvolvimento U rbano - criado pelo Plano Diretor Estratégico mas ainda não institucionalizado. Existem na Câmara de Vereadores - já em condições de votação - diversos Projetos de L ei para criação de C onselhos de Representantes ${ }^{4}$, um para cada uma das 31 Subprefeituras.

Todas essas situaçõ es colocam em evidência a presença de um debate sobre a política urbana no país, que, descrente de uma longa história de "planos no papel" , aponta agora para dois elementos fundamentais: a necessidade não só de recursos, mas também da unificação das ações - de que a criação do M inistério é evidência, e o quanto é fundamental o controle social da ação do Estado pela sociedade, por meio da participação da população de forma direta, não apenas através do voto.

A estrutura do Estado brasileiro, em sua conformação em três níveis de governo, prevê uma distribuição de competências com inúmeras sobreposições; são as "competências concorrentes", dos quais o nível estadual é o mais inespecífico. As poucas competências exclusivas são referentes à U nião e aos M unicípios. Aos Estados, compete "tudo que não Ihes seja vedado pela Constituição". D entre as exclusivas, pertencentes ao governo federal, estão, por exemplo, a moeda, a diplomacia, o idioma, enquanto aos municípios cabe legislar sobre assuntos de seu peculiar (diretrizes e controle de uso e ocupação do solo, transporte coletivo e taxação da propriedade imobiliária). 
Assim, cabe à U nião, num extremo, tudo o que envolve um caráter "abstrato", enquanto ao M unicípio, no outro extremo, cabe principalmente a "materialidade", ou seja, resguardar o "ambiente construído". Tanto é assim que o recurso eminentemente municipal é o proveniente do IPTU (I mposto Predial eTerritorial U rbano), cuja base de imposição é o conjunto material - de edifícios e lotes presentes no território municipal.

D entre a competências comuns da U nião, dos E stados, do D istrito Federal e dos M unicípios (art. 23) estão: zelar pela guarda da Constituição e das instituições demo cráticas; cuidar da saúde e da assistência pública; combater as causas da pobreza e promover a integração so cial. M ais especificamente vinculadas à cidade como estrutura física contam-se: proteger o meio ambiente e o patrimônio histórico, artístico e cultural; promover programas de construção de moradias e a mel horia das condições habitacionais e de saneamento básico. Estas últimas são áreas que necessitam de grande investimento. A possibilidade de uma mobilização mais ampla de recursos, incluindo financiamento e fomento de agências internacionais ou a articulação com o sistema Financeiro, evidentemente dizem respeito mais à U nião. No entanto, a específica competência municipal de "legislar sobre assuntos de interesse local" e de "promover, no que couber, adequado ordenamento territorial, mediante planejamento e controle do uso, do parcelamento e da ocupação do solo urbano", associada à competência comum, conforme acima, atribuem ao M unicípio ampla ação e responsabilidade.

\section{Leis, D ireitos e Exercício do Poder - um arcabouço em construção}

I niciadas com a promulgação da Constituição Brasileira de 1988, diversas transformações tiveram lugar nos campos do D ireito (definição de direitos), da representação e forma de exercício do poder, da fruição da propriedade. São questões centrais para o futuro de nossas cidades, mas nem sempre claramente correlacionadas e percebidas como tal.

A Constituição de 1988, que incorporou em seu texto um grande número de propostas populares, produto de longos anos de debates e lutas, introduziu al guns aspectos definitivamente transformadores para a política urbana no Brasil. O quadro de forças presente na ocasião implicou, no entanto, que a maioria dos aspectos mais inovadores tivessem sua aplicabilidade postergada ou diluída.Tanto é assim que um tema central para as cidades - a obrigatoriedade de que a propriedade cumpra sua função social teve sua aplicação condicionada à existência de um Plano Diretor M unicipal (para cidades com mais de vinte mil habitantes) e de uma L ei $\mathrm{N}$ acional regulamentando a matéria. C omo decorrência, a implementação da "função social da propriedade e da cidade" resultou impraticável por treze anos - até a aprovação do Estatuto da Cidade (em 2001) que, por seu turno, atendendo ao que a Constituição determinava, manteve o condicionamento da aplicação à existência de um Plano D iretor e a procedimentos sucessivos, 
não alternativos, o que implica, no mínimo, mais sete a dez anos para que seja aplicável. I sso significou um retardo de pelo menos vinte anos para que se efetivasse essa determinação constitucional.

N esse contexto, cumpre observar algumas outras formulações da Constituição e desdobramentos dela decorrentes, que têm maior implicação para as cidades brasileiras e para São Paulo em particular, e quais os encaminhamentos que tiveram nos últimos anos. A Constituição do Estado e a L ei O rgânica do M unicípio reafirmam e detalham as principais inovações da Constituição, e diversas Leis Federais e E mendas $C$ onstitucionais regulamentam diferentes aspectos. D entre esse conjunto, aponta-se a seguir alguns dos mais significativos, que permitem visualizar uma articulação entre política urbana municipal, inclusão social e desenvolvimento nacional.

Setores como saúde, educação e assistência so cial contam com diretrizes da U nião, que transfere recursos ao demais níveis, recursos esses que devem ser utilizados compulsória e exclusivamente para o respectivo setor. Esses recursos constituem Fundos, cuja aplicação deve ser orientada e acompanhada por conseIhos, dos quais participam o governo e sociedade civil organizada, com representação por segmentos. Vale ressaltar que o modelo do SU S (Sistema Ú nico de Saúde) tem sua referência nas propostas populares à Constituinte, e o Fundo $\mathrm{N}$ acional de $\mathrm{H}$ abitação (em tramitação) faz parte dos primeiros Projetos de Lei de Iniciativa Popular.

Princípio semelhante é seguido pelo Sistema $\mathrm{N}$ acional de G estão de Recursos $\mathrm{H}$ ídricos, que criou a forma de gestão do uso da água e do solo por unidades territoriais, que correspondem às bacias hidrográficas. Cada bacia hidrográfica deve constituir um conselho tripartite que delibera sobre recursos do fundo constituído para esse fim. No Estado de São Paulo, o sistema, aprovado em Lei desde 1991 (7663/ 91), encontra-se em esteagio de implantação mais adiantado. São ao todo 22 bacias no Estado, sendo que a Região M etropolitana praticamente coincide com os limites de uma delas - a bacia do Alto Tietê. D ada a complexidade da região a bacia é subdividida em cinco sub-bacias, cada qual com seu Conselho. A Lei Estadual no 9.866/97, que estabelece diretrizes e normas para a proteção e recuperação das bacias hidrográficas dos mananciais de interesse regional do Estado de São Paulo, assume esses mesmos princípios, considerando cada sub-bacia como unidade de planejamento egestão, atribuindo-Ihe um comitêgestor tripartite.

$\mathrm{N}$ a linha de conselhos como espaço de diálogo e de orientação de políticas públicas, a Lei Orgânica do M unicípio de São Paulo estabelece que "o Poder M unicipal criará, por lei, Conselhos a fim de assegurar a adequada participação de todos os cidadão em suas decisões". N esse sentido existem, no M unicípio de São Paulo, criados por L ei, mas em diferenciadas condições de operação e efetividade, conselhos de saúde, educação, assistência social, cultura, habitação, trânsito etransporte, meio ambiente e política urbana, além daqueles relativos a grupos suscetíveis: negros, mulheres, idosos e pessoas com necessidades especiais. 
M apa 1 - Região M etropolitana de São Paulo e Sub-bacias do Alto Tiete.

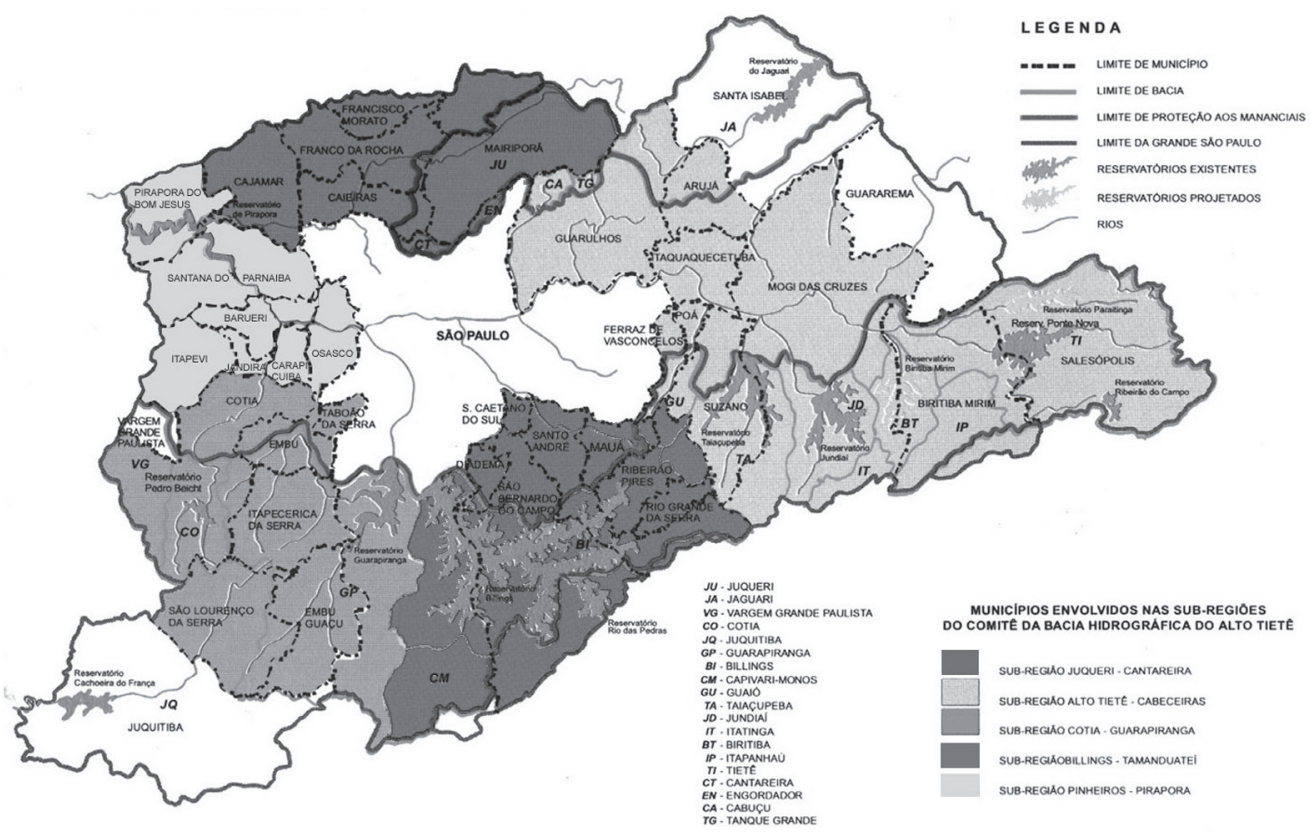

Fonte: Secretaria do M eio Ambiente da Prefeitura de São Paulo (SM A/ CPLA). U ma nova política dos mananciais. São Paulo, 1997, p. 11.

No bojo do novo quadro institucional brasileiro, dentre os aspectos que dizem respeito mais diretamente ao município e à cidade, está, sem dúvida, 0 conteúdo do Estatuto da Cidade, do qual se pode destacar alguns aspectos centrais: estabelecer as condições e viabilidade para o cumprimento da função social da propriedade - impondo sanções à não utilização dos imóveis ociosos; instituir o U sucapião Especial U rbano e a C oncessão E special de U so, ambos aplicáveis inclusive de modo coletivo (facilitando a urbanização de favelas e de assentamentos sem lote definido) e incluir entre as atribuições do $\mathrm{M}$ inistério Público a $\mathrm{O}$ rdem U rbanística. U ma vez que o Estatuto da Cidade "estabelece normas de ordem pública e interesse social que regulam o uso da propriedade urbana em prol do bem coletivo, da segurança e do bem-estar dos cidadãos, bem como do equilíbrio ambiental" (art. $1^{\circ}$, parágrafo único), a inclusão da O rdem U rbanística como atribuição do $\mathrm{M}$ inistério Público consagra a natureza de bem coletivo atribuído à cidade, já que cabe ao M inistério Público, conforme sua atribuição definida na Constituição a "defesa dos interesses sociais", zelando pelos interesses difusos e coletivos.

A relevância desse quadro legal é dar sustentação jurídica às conquistas sociais. No entanto, só as Leis nada asseguram, apenas abrem espaço para a ação dos movimentos sociais e da sociedade organizada de modo geral, mas se tornam letra morta se não houver interlocutores constituídos e pressão social. Pode não significar muito, mas, numa sociedade patrimonialista (nos termos de Raimundo 
Faoro), em que as relações sociais são tradicionalmente as de favor e dependência, não é pouco avanço.

O Estatuto da Cidade, sendo referente ao M unicípio, ressalta a importância atribuída ao entorno mais próximo, aquilo que se conhece de perto - a cidade. N esses termos, marca uma possibilidade de democratização e acesso, conforme evidenciaJ osé M arti "E sa es la raiz y esta es la sal de la libertad - el M unicipio" 5 .

O risco é que a multiplicidade de espaços institucionais de participação acabe pulverizando a representação, criando uma miríade de pequenos espaços, de difícil diálogo entre si, e que, em lugar de esses espaços propiciarem ações integradas e desencadeadas de modo democrático, simplesmente criem um alto nível de entropia e dispersão, tornando o caminho desacreditado. Para que se esteja atento, nunca é demais lembrar M aquiavel, cuja estratégia era “ dividir para governar".

\section{A estrutura física da cidade e a regulamentação urbanística}

D esigna-se usualmente como Cidade de São Paulo a área urbanizada contínua, cujo centro é o município de São Paulo: Região M etropolitana de São Paulo - RM SP, cujo índice de urbanização é de $96,6 \%$. O núcleo inicial da cidade surgiu em 1554 entre os rios Tamanduateí e Anhangabaú, pequenos afluentes da margem esquerda do rio Tietê. Ao longo de seus primeiros quatro séculos expandiu-se por toda a área relativamente plana, limitada ao norte pelo rio Tietê e sua várzea, sucedida pelos contrafortes da serra da C antareira, e a oeste pelo rio Pinheiros, com sua várzea. Além desse território, segue-se um relevo movimentado, com declividades em torno de 30\%, conhecido como "mar de morros".

A principal fonte de captação de água potável da cidade é, desde o início do século XX, o conjunto captação/ tratamento situado na serra da Cantareira, área adquirida pela companhia de águas para esse fim. $\mathrm{N}$ as primeiras décadas do século XX foram construídas ao sul da cidade as represas de Guarapiranga (em 1908), utilizada a partir da década de 1920 para abastecimento de água, e a represa Billings (em 1925), com o objetivo de gerar energia, aproveitando a forte queda (700 m) da vertente marítima existente mais ao sul. As represas foram real izadas desapropriando-se estritamente a área de inundação, cujas margens permaneceram como propriedade dos donos originais. Com o crescimento da cidade, mais água foi necessária e inclusive a represa Billings passou a ser parcialmente utilizada como manancial de água potável.

Para proteção de seus recursos hídricos a cidade conta, desde 1934, com 0 Código das Águas, legislação estadual que estabelece orientações para o aproveitamento dos recursos hídricos, definindo ao longo dos cursos d'água e nas margens das represas faixa de proteção non edificandi, cujos limites não poderiam, portanto, ser incluídos nas áreas de venda de eventuais loteamentos. A partir de 1972 foi aprovada legislação municipal de controle de uso e ocupação do solo para a região, restringindo o uso e a densidade e, em 1976, uma lei metropolita- 
na com igual fim, já que a área das bacias extrapolava os limites do município de São Paulo.

Vale ressaltá-lo porque, na última década, do ponto de vista demográfico e de um modo geral, foi fora dos núcleos centrais mas dentro das regiões metropolitanas, particularmente em São Paulo, que ocorreu o maior crescimento de população, com a conseqüente intensificação dos processos de suburbanização e periurbanização precária, ao lado da implantação segregada dos mais diversos tipos de condomínios e loteamentos fechados, que abrigam populações de renda mais alta.

M apa 2 - Região M etropolitana de São Paulo. Lei de Proteção dos M ananciais

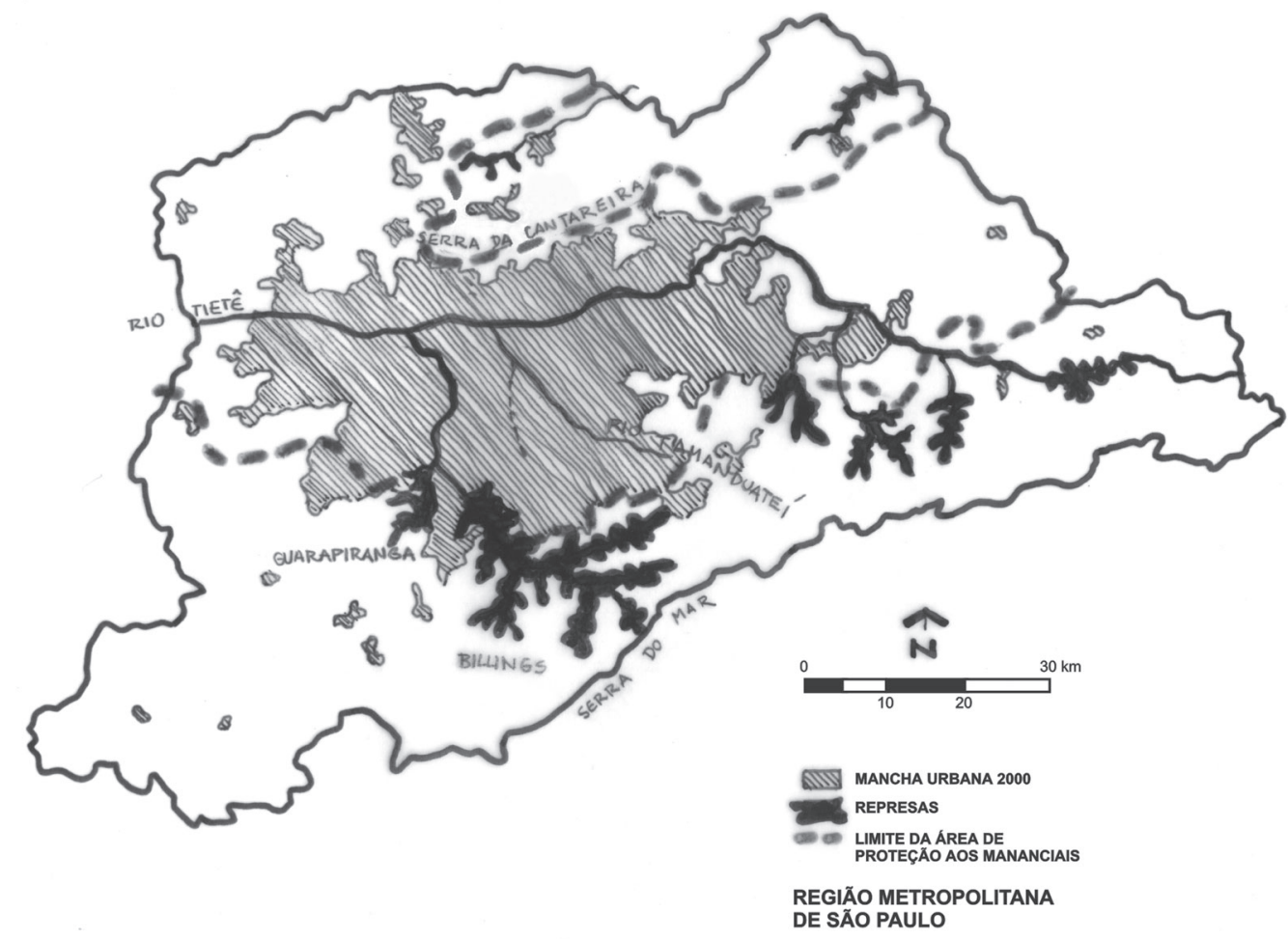

Fonte Emplasa, 2001.

Assim como o próprio urbanismo, o direito urbanístico, que surge pouco depois, tem a perspectiva de melhorar o ambiente urbano, num momento de intensa urbanização. Enquanto o urbanismo desenvolve modelos, o direito urbanístico estabelece as correspondentes regulamentações, tendo ambos por o bjetivo um controle funcional, sanitário e ambiental da estrutura física das cidades. Este último regulamenta ainda as relações sociais e as formas. Ponto de contato entre os saberes e procedimentos jurídicos e urbanísticos, move-se dos direi tosà arquitetura - operando num campo em que o domínio dos instrumentos é um pouco frágil, pois o encadeamento: proposta - ação - conseqüência, não é inteiramente previsível nem unívoco. 
Tornando o quadro ainda mais complexo, no direito urbanístico a relação instrumento/ impacto é afetada por inúmeros outros fatores, como a cultura local, as condições econômicas e de mercado, o quadro institucional responsável por sua implantação e fiscalização, os parâmetros utilizados para aval iação. Também não é simples a tipificação do delito - e conseqüentemente a correspondente sansão e, ainda, a efetividade da sanção como reparação. A desconsideração de mecanismos econômicos na formulação das regulamentações e instrumentos urbanísticos leva, no caso brasileiro - como em inúmeras outras regiões com perfil sociocultural e político semelhantes, onde controle, fiscalização, sansão são quase sempre insatiffatórios - a distorções que causam efeitos exatamente opostos aos pretendidos. São diversos os exemplos na R egião M etropolitana de São Paulo.

U m dos casos significativos, porém mais complexo do que isso, é o da legislação referente à proteção dos mananciais (área considerada de controle especial - Z8, na legislação municipal paulistana de 1972, posteriormente incorporada à estadual - L eis898/ 75 e 1172/ 76). A modalidade da legislação aplicada - fortes restrições ao uso e ocupação do solo, visando ao controle da densidade para evitar a poluição da represa - teve como decorrência a queda do valor de mercado da terra. $\mathrm{N}$ a absoluta falta de al ternativas de moradia para a população de mais baixa renda, houve ocupação dessa área, de modo informal e precário. N um contexto em que as políticas públicas são absolutamente insuficientes para promover condições ad equadas e universais de acesso e usufruto da cidade, a "regra não escrita" resultou como a da informalidade - eufemismo para designar à margem da Lei. Essa região protegida registrou, nas últimas duas décadas, um dos maiores índices de crescimento do conjunto da cidade.

N esse quadro, a principal questão ambiental urbana é hoje, em São Paulo, antes de tudo, um problema de moradia e de carência ou insuficiência de política habitacional.

O período que vai do final dos anos de 1940 até meados da década de 1970 foi marcado pelo mais intenso ritmo de urbanização que o país já teve. I sso significou a expansão periférica das cidades, feita por meio de loteamentos sem qualquer cuidado. Apenas na década de 1970 tem início uma legislação com alguma exigência de infra-estrutura e espaços públicos. A legislação paulistana que impõe regras de qualidade aos loteamentos, conforme acima referido, é de 1972; a legislação nacional sobre esse assunto é de 1979 (6766/ 79). A incorporação de controles ambientais é instituída sob forma de Lei em São Paulo em 1975, com a Lei de Proteção aos M ananciais - 898/ 75 e 1171/ 76. Ao serem aprovadas, essas duas L eis (Proteção aos M ananciais e L oteamentos) continham dispositivos admitindo a regularização, sob forma de exceção, do que já havia sido implantado, criando a figura do empreendimento adaptado. Tais procedimentos e condições são expressos nos seguintes diplomas legais:

- Decreto Estadual 9714/77, referente à regularização com adaptação das exigências da L ei dos M ananciais; 
- Resolução SN M -093/ 85, permitindo, nos termos do art. 40 da Lei 6766/ 79, a regularização de loteamentos implantados anteriormente à L ei desde que promovida por Prefeitura ou órgão municipal competente e fora de áreas de proteção aos mananciais.

M apa 3 - Região M etropolitana de São Paulo. Crescimento demográfico 1991-1996

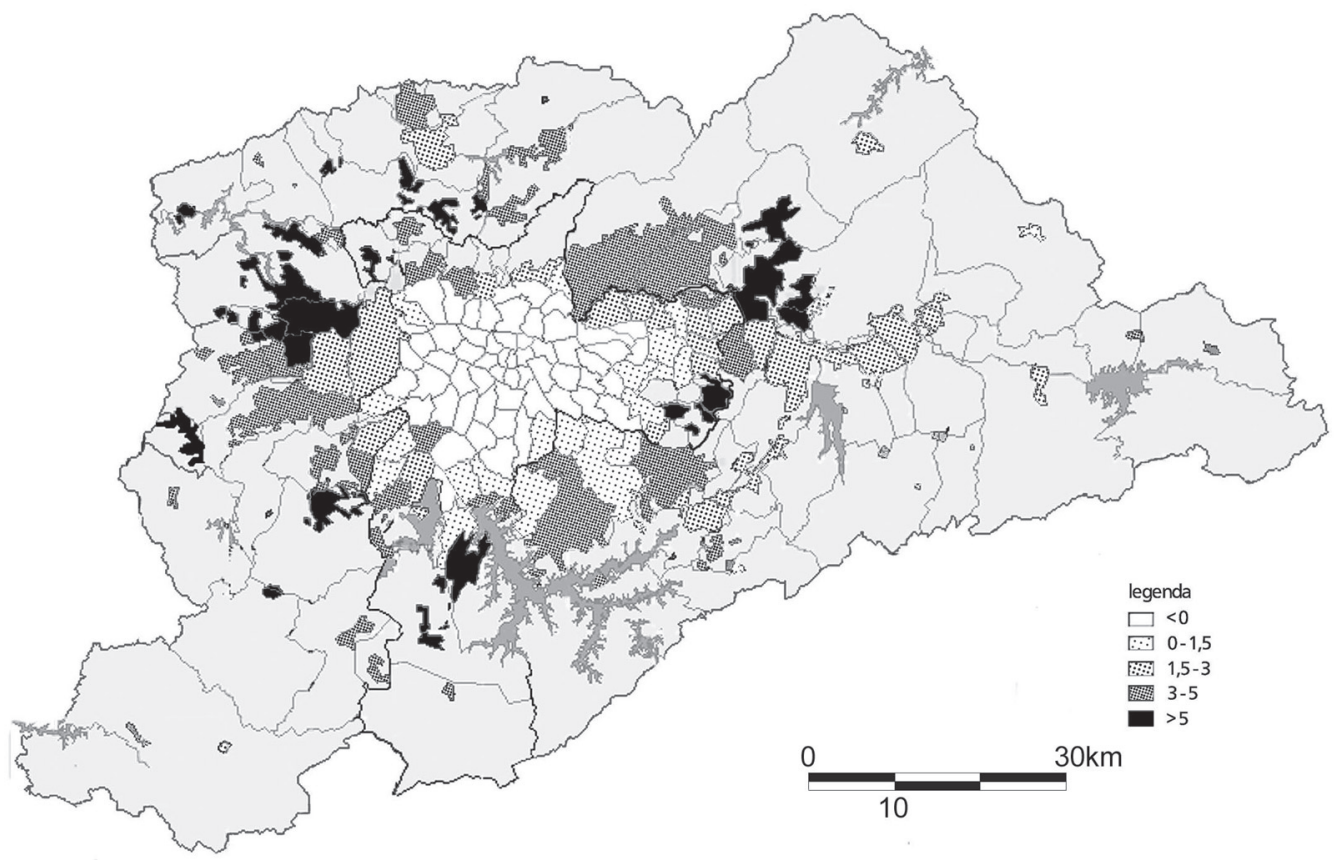

Fonte do mapa base: Relatório de Pesquisa. R M SP: Globalizacão da economia e impacto na etrutura urbana. Coord. Sueli Schieffer. FAU -U SP, 1998.

Fonte dos dados: Seade, informação dos municípios paulistas. Consulta eletrônica, abril 2001.

$\mathrm{N}$ as áreas de Proteção a M ananciais - particularmente aquelas ao sul da cidade de São Paulo - bacias das represas Guarapiranga e Billings, são diversos os loteamentos produzidos literalmente à margem de qualquer lei, implantados após a promulgação da legislação de proteção dos mananciais mas, a maior parte deles, tem algum pedido de aprovação ou mesmo planta aprovada na década de 1950, mas só se implantou efetivamente nas duas décadas seguintes, em geral sem maiores preocupações com a regularidade urbanística ou legal. C om a interdição do registro em Cartório de Registro de I móveis das propriedades em loteamentos irregulares, iniciada com a L ei $6766 / 79$, houve uma verdadeira corrida à regularização e à criação das legislações de exceção acima referidas. Como as condições físicas dos loteamentos eram infinitamente inferiores ao estabelecido nas novas leis, a grande expectativa dos loteadores passo u a se comprovar que estavam implantados antes de 1979, e antes de 1975, se na região dos mananciais. 
Esse quadro é o que está presente até hoje, com reduzidas condições de solução. O Plano Diretor Estratégico do M unicípio de São Paulo, aprovado em 2001, apresenta a alternativa de constituir Zonas E speciais de I nteresse Social - ZEIS, 0 que, no entanto, ainda suscita debates com a legislação estadual. A ordem urbanística, nesse caso de assentamentos populares junto aos mananciais da cidade de São Paulo, envolve a aquisição de direitos (à moradia e à cidade) devendo ser dada sem prejuízo da qualidade da água que abastece seis milhões de pessoas ${ }^{6}$. $\mathrm{N}$ esse sentido, tem-se trabalhado ${ }^{7}$ na busca de alternativas técnicas que permitam a manutenção dos assentamentos consolidados e a preservação da qualidade e quantidade da água, para que se possa propor solução de regularização através da celebração de compromisso de ajustamento de conduta ou de reparação de danos entre o conjunto de envolvidos ${ }^{8}$.

Considerando-se a condição social e o fato de tais alternativas poderem promover, de fato, a desagravação da irregularidade (portanto, atuarem no espírito da lei) podem representar possibilidade juridicamente aceitável, ainda que os termos estritos da lei não possam ser atendidos. D esse modo, a função social, conforme determina o Estatuto da Cidade, daquele pedaço de cidade, estaria sendo cumprida, por garantir abrigo à população que não dispõe de outras alternativas, ao mesmo tempo em que mantém as condições da reserva de água para consumo urbano.

É da natureza do D ireito assegurar direitos. No entanto, o D ireito, de um modo geral, e particularmente o direito urbanístico, é muitas vezes invocado como recurso para manutenção do status quo em detrimento de processos de transformação que justamente visem a assegurar direitos. As transformações, principalmente as urbanas, acabam sendo feitas informalmente ou ao arrepi o da lei.

U ma sociedade que não consegue prover o mínimo necessário à adequada condição de abrigo de parte de seus membros, convive pacificamente com a tolerância, como forma de provimento - desde que afastada de determinados pontos mais visíveis ou mais valorizados. Por todos esses aspectos, o direito urbanístico é talvez uma das áreas do Direito em que o espírito da lei e o produto ou conseqüência da aplicação das normas sofram maior discrepância: a ci dadeilegal predomina sobre a cidade legal. N esses termos, a ação de reparação de danos e ajustamento de conduta é um importante avanço e contribuição - não só à matéria urbanística, mas também à concepção de pena, de um modo geral. É talvez uma bela luz sobre um certo cinismo nacional encoberto pelo eufemístico jeitinho brasileiro.

N esse contexto, o conceito de direitos difusos, por natureza coletivos, pode representar uma revigoração do D ireito e uma possibilidade sensível de interferir construtivamente no conflito entre assegurar direitos pela manutenção do status quo e assegurar direitos ao conjunto da sociedade, que não os tem, na prática, 
reconhecidos. Por outro lado, a prática do ajuste de conduta pode também representar importante campo para experimentação no sentido da formulação de legislações mais condizentes com a realidade e a cultura brasileira do que os modelos e formulações produzidos em outros contextos e que por séculos insistimos em importar, com pouquíssimas mediações.

Alterar as atuais limitações implica rediscutir model os urbanísticos e procedimentos de trabalho e de proposição de regulamentações. U m método de trabalho que parta não de traduzir conceitos em desenho ou em normas, mas de construir práticas, propostas e modelos que respondam à nossa efetiva realidade, a nossas limitações institucionais - criativamente, sem preconceitos, já que 0 usual ou o conceitualmente irrepreensível, formalizado no papel ou nas normas, em nossas condições reais -, tem muitas vezes levado a desastres urbanísticos e ambientais. D eve-se buscar a melhor eficiência e funcionalidade do conjunto, que qualifique as condições de vida na totalidade da cidade, inclusive porque aspectos como a preservação da água de abastecimento e a funcionalidade da cidade dependem da somatória de ações, da total idade e não de ações exemplares porém pontuais.

Esse aspecto conduz a mais uma reflexão sobre a funcionalidade e eficiência da cidade. 0 quadro recente da economia, ao mesmo tempo em que reduz 0 emprego estável e de qualidade para as parcelas mais despreparadas e frágeis da população, requer condições de funcionalidade urbana de qualidade superior, 0 que vem se constituindo à custa de concentração de investimentos em determinadas áreas da cidade ao lado de reduzida oferta de serviços públicos, onde não há mercado, e em assentamentos populares ilegais. Essa condição recente vem a ampliar um passivo histórico (que lhe antecede) de assentamentos irregulares, à margem da lei e do mercado formais, localizados justamente nas áreas ambientalmente mais frágeis.

Se a dualidade de condições urbanas edificadas, com "ilhas de eficiência" na cidade vem viabilizando, nos anos recentes, o funcionamento dos negócios e empresas da nova economia, as condições ambientais, que são indivisíveis, começam a demonstrar seu limite, chegando a situações críticas que afetam não só a parcela tradicional e excluída, mas toda a comunidade - de pessoas físicas aos próprios negócios - como é o caso do limite da disponibilidade de água potável, da poluição dos mananciais e redução de sua carga abaixo dos níveis de segurança, das enchentes, da crise de energia elétrica e da proliferação de doenças como a dengue, transmitida por vetores.

Enfrentar esses temas deixa de ser apenas uma questão de justiça social, mas também de viabilidade de qualquer desenvolvimento. $M$ ais do que 0 trânsito congestionado e limitações das redes de infra-estrutura, é a falta de alternativas para a ampla questão so cial que embarga um melhor funcionamento da cidade, uma maior produtividade. N esse contexto, a formulação de políticas urbanas no Brasil, como também nas metrópoles de países periféricos, particularmente da 
América L atina, exige repensar o urbanismo: se, nas metrópoles, as demandas de funcionalidade do setor produtivo internacionalizado se associam a um quadro de degradação sócio-ambiental, o que significa eficiência?

$\mathrm{N}$ um modelo de desenvolvimento que resulta em ser concentrador desde o nível local ao internacional e global, não há urbanismo que dê conta de qualificar o espaço urbano, particularmente em sua dimensão ambiental. É inconsistente pensar em qualidade ambiental sem associá-la a desenvolvimento social.

\section{M odernização, sociedade e espaço construído}

Discutir modernização hoje requer um retorno às origens do termo modernidade e, nesse sentido, é conveniente lembrar que ele surge com a revolução industrial, concomitantemente a diversas outras construções, tal qual 0 Estado nacional. M odernidade, no final do século XIX, está associada à idéia da desterritorialização, do desenraizamento de pessoas e de produção; é o oposto da concepção tribal. M as comporta um novo enraizamento, uma nova articulação, no território que se designa por $\mathrm{N}$ ação, espaço integrado por determinada identidade e tempo comuns.

O Estado-nação existe a partir da revolução industrial. É integração cultural e de mercado - um mercado nacional, passível de existência somente após a revolução industrial. Sem mercado nacional não se consubstancia o Estado-nação. H oje, com os processos de internacionalização e globalização do mercado, o Estado-nação se enfraquece e a geocultura que a ele corresponde deixa um vácuo cujos desdobramentos ainda são pouco claros. Conceitualmente, no bojo da globalização parece ser possível ser moderno sem ser nacional.

$\mathrm{N}$ esses termos, se de um lado a modernidade se expressa por meio do cidadão, que consome no mercado mundial e, portanto, todos os não-consumidores tornam-se excluídos, pode-se, por outro lado, entender modernização como eliminação de aspectos arcaicos, pré-modernos. Essa última qualificação identifica modernização menos pela presença isolada de manifestações ou signos da cultura contemporânea, mas principalmente pela redução de ocorrências, produtos, espaços e práticas arcaicas e discriminatórias - modernização como um processo civilizatório.

É nesse contexto que cumpre discutir o conteúdo de "modernização" na cidade. Espaço construído é interação com a sociedade e com a economia. Podese falar em modernização da cidade ou de modernização da sociedade por meio da cidade. Assim como se pode falar de desenvolvimento urbano ou de desenvolvimento social por meio da cidade, por meio de políticas urbanas.

A pesar do crescente índice de desemprego e precarização do trabalho nos últimos vinte anos, as condições sociais, essencialmente as ligadas ao consumo urbano, tiveram, na maior parte das cidades brasileiras, al guma mel horia. Ascondições e serviços urbanos se mostram efetivamente como a melhoria computável nas condições de vida dos mais pobres. Assim, a cidade, com seus serviços, vem 
representando uma perspectiva de escape à completa "exclusão social". I sso fez com que fosse percebida por grandes parcelas da população mais como forma de inserção social que como estrutura física. E ssa condição fica evidente quando se observam as características e demandas dos movimentos sociais urbanos, que, particularmente a partir da década de 1970, lutam por melhor qualidade de vida, priorizando questões como saúde e moradia.

A década de 1990 evidencia um quadro de deslocamento de população dos núcleos metropolitanos que passam a uma condição de crescimento populacional negativo e crescimento muito intenso em seu anel de distritos e municípios periféricos. I sso termina por implicar em menor acesso a equipamentos e infra-estrutura urbana - ou seja, perda relativa na distribuição do produto social via meio urbano. Recuperar esse acesso é desafio fundamental - daí a importância das políticas de repovoamento do centro e de áreas equipadas que perderam população.

Admitindo-se que alguma transferência de excedente para as populações mais pobres venha se dando menos por meio de salários, e mais por políticas urbanas, pode-se proceder a uma reflexão teórica no sentido de descrever e avaliar a forma como estas políticas urbanas têm interferido na geração e distribuição do excedente na Região M etropolitana de São Paulo, e de produzir indicadores que expressem a efetiva conseqüência dessas políticas tanto para o bemestar da comunidade como para o desenvolvimento econômico. A expectativa é de que seja possível construir e praticar um "urbanismo includente".

Se a questão que hoje se coloca é a do debate sobre o modelo de desenvolvimento em termos econômicos, então se deve colocar também a do modelo do desenvolvimento urbano e metropolitano. É fundamental assumir que, sem investimento e prioridade ao desenvolvimento social, será, no mínimo, impossível atingir um desenvolvimento econômico que assegure condições ambientais básicas, ainda que todas as indústrias estejam sujeitas a um forte e eficiente controle ambiental - o que já vem, de fato, progressivamente ocorrendo, não necessariamente por uma "consciência ambiental", mas certamente por conta das normas internacionais de certificação de qualidade.

Essas reflexões para a discussão do papel da cidade na perspectiva da modernização - entendida aqui como a superação do arcaico, particularmente nas condições sociais - e de como a cidade participa desse processo. D evem ser considerados, para tanto, os canais existentes e os canais por fazer, os quais serão melhor discutidos nos próximos itens.

\section{A disputa por recursos}

U $m$ dos efeitos sociais da globalização econômica sob a égide do mercado é o de tornar a cidade depositária de excluídos do sistema econômico, pois este não se interessa por incorporar o conjunto da população. Tanto o emprego como o salário não são mais uma certeza, e conquistas sociais se desfazem. A cidade, com seus serviços, é avidamente procurada como uma alternativa à "exclusão 
social" e, conseqüentemente, percebida por grandes parcelas da população mais como forma de inserção social do que como mero objeto físico.

Conforme enunciado no item anterior, o conteúdo - inserção social via benefícios urbanos - parece ser, em São Paulo, tanto quanto em quaisquer cidades de grande porte em regiões com grandes disparidades de acesso à renda, função essencial do meio urbano. Seus diferentes componentes são, no entanto, geralmente percebidos de forma desarticulada, descolada de uma compreensão mais global da cidade. $\mathrm{N}$ esses termos, que significado pode ter o urbanismo ou 0 próprio desenvolvimento urbano?

Para a população excluída, a inserção é prioritária, portanto, a questão urbana tende a se mostrar mais como uma disputa por espaço social do que como um debate puramente urbanístico. Assim, à medida que os grupos excluídos redefinem a noção de cidade conforme suas efetivas necessidades, espera-se que os movimentos populares urbanos construam essa redefinição no sentido de ressaltar que a cidade tem papéis e funções diferentes para cada grupo. Remete-se assim a questão urbana para mais do que uma disputa pela forma e qualidade do espaço ou uma relação reivindicatória com o Estado (mais serviços, mais equipamentos), mas para uma verdadeira disputa na sociedade, onde a construção do orçamento municipal pode assumir um caráter muito mais amplo.

Ao mesmo tempo, é conveniente lembrar que o Estado, no Brasil nunca foi efetivamente universalista, apesar de suas Constituições desde há muito garantirem isso. Alternando-se entre autoritário e paternalista e pouco eficiente, sempre teve, no entanto, alguma visibilidade. I sso permitiu, face à intensa urbanização das décadas de 1950 e de 1960 o surgimento, nos anos de 1970, de movimentos urbanos de caráter reivindicatório e, posteriormente, de fôlego mais amplo, de caráter propositivo. M ais recentemente, o mercado, apresentado como parafernália da eficiência e produtividade no âmbito mais amplo da economia, apenas dá conta, também no âmbito da cidade, de desenvolver-se como mercado, conforme seus objetivos e natureza - seja no tocante à produção do espaço (em que busca oferecer os produtos de maior aceitação e liquidez para consumidores individuais e não para uma coletividade), seja na produção de serviços que só são oferecidos em áreas de grande demanda.

Assim, face à tendência mundial de ênfase ao mercado e retração do Estado em suas atividades de cunho social, impõe-se o desafio de assegurar formas institucionais e de gestão da cidade, que viabilizem condições e continuidade de serviços à comunidade, garantindo seu caráter universal. I sso requer tanto um trabalho teórico reflexivo como a ampliação de espaços políticos e constituição permanente de interlocutores. 0 empenho nessa nova institucionalidade, passível de efetivação via presença popular nos espaços institucionais de participação, é requisito básico tanto para garantir o fluxo de investimentos para esses setores como para fiscalizar a gestão pública, desmontando a tradição e o argumento de que as estruturas públicas existentes são perdulárias ou corruptas. 0 amplo es- 
pectro de Conselhos e Comitês com composição majoritária da sociedade, conforme referido em itens anteriores, pode constituir-se como esse espaço.

\section{U m debate a ser formulado}

Ao lado dessa disputa pelo direcionamento de recursos diretos, concreta e visível, que se expressa nos O rçamentos e nos Conselhos, há um debate a ser formulado, sobre valores cuja existência e manifestação carece de explicitação.

A cidade - o ambiente construído, como atividade econômica é um setor em expansão. N ela ocorrem, simultaneamente, aumento da terceirização da produção e ampliação do setor de serviços. Somados esses fatores, o espaço urbano torna-se cada vez mais valorizado. 0 valor do espaço em si e do imobilizado (edificações e principalmente infra-estrutura) é muito significativo no montante da atividade econômica, decorrendo daí uma acumulação especificamente urbana. A base física e o lugar não são mais apenas uma contingência, mas objetos de uma acumulação especificamente urbana, tanto que grande parte dos conglomerados econômicos auferem, sob alguma forma, ganhos de origem imobiliária.

$\mathrm{H}$ istoricamente, a cidade é vista apenas como suporte físico da atividade econômica. Seus desafios vêm sendo, portanto, questões técnicas ou materiais de um modo geral, ou seja, tarefa de engenheiros, arquitetos e artistas. Seu novo status, conforme acima registrado, é extremamente relevante para o significado que possam ter as regulamentações urbanísticas e formas de intervenção urbana e requer uma verdadeira revolução de conceitos, técnicas e procedimentos.

Anteriormente à industrialização, quando a acumulação procedia primordialmente do campo, a cidade representava apenas abrigo e lugar do mercado portanto, com pouco significado econômico para a atividade produtiva principal, responsável pelo grosso da concentração de capital. Essa condição é tão explícita e a terra urbana tão sem valor econômico que em nosso país, até meados do século XIX, vamos encontrar, na maioria das cidades, o rossio - terra de uso público destinada ao plantio e utilizada como reserva para a construção de moradias de cidadãos que delas necessitassem. A terra só adquire estatuto de propriedade, e portanto de mercadoria passível de compra e venda, a partir de 1850, com a L ei de Terras, que separa efetivamente o que é público do privado ${ }^{9}$.

No processo de industrialização, sendo a indústria nascente intrinsecamente urbana, o território da cidade passou a valorizar-se como suporte para as atividades, fossem elas a produção ou a reprodução social. De qualquer forma, seu papel predominante permanece sendo o de estrutura física. N essas condições é que se desenvolveram as regulamentações urbanísticas, tendo por objetivo um controle sanitário e ambiental.

$\mathrm{N}$ as circunstâncias atuais em que a promoção imobiliária, tanto quanto as valorizações das localizações, representam parcela importante da economia, há valo res decorrentes da cidade significativos como parte dos processos de geração e transferência de renda. 
O bservando esse crescente valor produzido pela aglomeração urbana em si, a Constituição, e posteriormente o Estatuto da Cidade esboçaram algumas possibilidades no sentido da socialização desse valor e como forma de coibir a retenção de imóveis urbanos como prática especulativa. São respectivamente os princípios da outorga onerosa e da utilização compulsória de imóveis não utilizados ou subutilizados. Ambos são instrumentos de efetivação do que a Constituição designa por função social da propriedade e da cidade. O Plano D iretor E stratégico de São Paulo incorporou a ambos, porém com grandes mediações. A mais evidente se expressa na figura das operações urbanas, que terminam por parcialmente anular o potencial da outorga onerosa.

A cidade de São Paulo, assim como outras metrópoles brasileiras, concentra seu investimento público grandemente na região ocupada pelos setores de mais alta renda e mais valorizados, conforme apontam inúmeras pesquisas empíricas $^{10}$. As o perações urbanas, que, por definição, devem contar com o interesse do mercado para sua implementação, encontram-se localizadas justapostas a essas áreas mais qualificadas - como av. Faria Lima, Águas Espraiadas, Água B ranca etc. N essas condições é que se pode avaliar o efetivo impacto desse instrumento, que se justifica com 0 argumento de que em áreas onde o mercado imobiliário tem interesse, pode ser produzida infra-estrutura e melhorias sem necessidade de investimento do Estado. A outorga onerosa (pagamento pela construção acima do coeficiente básico) deve ser aplicada dentro do perímetro da operação. Com isso, o Estado se desoneraria, direcionando recursos próprios para áreas mais carentes.

Seria verdade não fossem os argumentos já desenvolvidos anteriormente, e se um dos recursos mais frágeis no poder público não fosse justamente a capacidade de gestão. Como ela é finita, se o poder público ocupa sua restrita capacidade no gerenciamento dessas áreas, evidentemente estará deixando de fazê-lo em algum lugar - todos eles certamente mais carentes.

Por outro lado, cabe indagar: de que maneira o investimento público e privado nessas áreas poderá, em lugar de tornar a periferia ainda mais periferia, propiciar-Ihe ganho de qualidade? A parentemente é impossível e contraditório. Criar essa possibilidade é o requisito para que tal instrumento se justifique. D esvendar o segredo dessa esfinge significa colocar em discussão modelos de desenvolvimento. É o que nos permitirá pensar a sociedade brasileira, seu espaço e sua arquitetura para o século XXI.

$\mathrm{N}$ a recente formulação do Plano $\mathrm{D}$ iretor paulistano, pela primeira vez, setores populares - especialmente movimentos organizados de luta por moradia - foram incluídos no debate, e suas propostas incorporaram-se ao produto final: a delimitação de ZEIS (Zonas Especiais de Interesse Social) consta no texto da lei.

Conforme se poderia supor, a lei finalmente aprovada não expressa exatamente um projeto em comum, mas uma so matória das aspirações de três vertentes. Sinteticamente, estas aspiraçõ es podem ser caracterizadas da seguinte manei- 
ra: o setor imobiliário, que vai contra a outorga onerosa e é a favor da ampliação de coeficientes de aproveitamento em determinadas regiões; o setor popular, favorável às ZEIS e às condições de incentivo à construção de $\mathrm{H}$ abitação de Interesse Social; e os setores compostos pela classe média, que defendem a manutenção das zonas exclusivamente residenciais.

0 resultado foi a garantia de alguns objetivos e propostas de cada um dos grupos, de modo que todos pudessem ser contemplados. H ouve, entretanto, um senão: se a delimitação de ZEIS, nos locais em que foram aplicadas, pode significar pouco ao setor imobiliário - por se tratarem de áreas fora de seu campo de atuação, a outorga onerosa, como possibilidade de socialização da valorização imobiliária, não. No cômputo final, sua efetividade acabou reduzida pela concorrência com as operações urbanas, em que a outorga é aplicada no próprio local, repondo seu custo ao investidor, pela realização da valorização imobiliária no próprio local.

Pensamos que estes aspectos ilustram suficientemente a dimensão econômica, na cidade de São Paulo, da competência municipal de "promover, no que couber, adequado ordenamento territorial, mediante planejamento e controle do uso, do parcelamento e da ocu pação do solo urbano". Permitem também situar a questão no campo da política urbana e de sua relação com a inclusão social.

\section{U $\mathbf{m}$ papel para a U niversidade}

A pesar de a extensão fazer parte das atribuições acadêmicas, com freqüência assume um caráter de "prestação de serviços" ou de "assistencialismo". Representa - quando existe, a única parcela da produção universitária que se ocupa do setor popular. 0 desafio que se coloca é então o de se inserir essas práticas no centro da produção principal do conhecimento, na linha de ponta da pesquisas e do ensino. É necessário que toque efetivamente nos constrangimentos que bloqueiam a ação - grande parte deles expressão da falta não de tecnologia e de conhecimento, mas de humildade para uma ação intersetorial e que reconheça no outro um interlocutor.

A maior parte do crescimento das cidades brasileiras não conta com a colaboração do conhecimento técnico formal ou do financiamento público ou privado. A maior parte das moradias urbanas nas metró poles e grandes cidades é feita fora do mercado legal privado ou mesmo das políticas de promoção pública e ao largo da legislação urbanística e ambiental existente, sem qualquer apoio técnico.

É em resposta a esse quadro que algumas iniciativas vêm se desenvolvendo no meio acadêmico ${ }^{11}$. A experimentação e a prática fazem parte da construção teórica. 0 desenvolvimento de projetos e sua aplicabilidade são essenciais a essa construção. O laboratório nas ciências sociais aplicadas é a sociedade; em arquitetura e urbanismo, congrega sociedade e espaço. Fazer ciência nessas áreas não pode ser apenas observação. D aí a importância dos projetos concretos, das experiências práticas. Com base nos projetos-piloto podem ser construídos ver- 
dadeiros procedimentos metodológicos. Se o tempo e recursos institucionais são limitados, a escolha de determinado foco esvazia a possibilidade de agir em outro. Assim, é fundamental que os focos escolhidos, particularmente numa universidade pública, visando à universalidade, tenham a perspectiva das necessidades e demandas da maioria - com excelência e melhor tecnologia.

I sso não quer dizer que se possa deixar de conhecer, e no mais alto nível, os circuitos mais restritos de exclusividade e fortemente concentrados em que opera o grande capital. M as é fundamental avaliar o impacto dessas ações sobre os setores majoritários, de forma que esse conhecimento e essas ações não representam mais investimento público direcionado sempre no mesmo sentido, para setores já contemplados. U m bom exemplo desse debate, do ponto de vista dos estudos urbanos, é o tema das designadas operações urbanas, figura adotada na Lei do Plano D iretor Estratégico do M unicípio de São Paulo.

A massa de investimento social representado pelos professores e alunos na universidade pública é algo relevante que, no entanto, jamais quantificamos. É com essa quantidade de investimento público que estamos lidando. Para onde se dirigir é para onde estaremos dirigindo esse inestimável investimento.

As experiências dos laboratórios da habitação acadêmicos, presentes em diferentes unidades na década de 1980, propiciaram um conhecimento e uma experimentação que permitiram a viabilização de empreendimentos autogeridos, com assessoria própria e qualidade de projeto. Levaram ao que se designou "direito à arquitetura", com diversas experiências em administrações municipais populares e à constituição de um conjunto de escritórios profissionais especializados - as "assessorias". D aí advém a percepção de que os percursos acadêmicos e de pesquisa são capazes de transformar-se em conceitos e práticas profissionais.

Foi também a vinculação entre conceito e experimentação e domínio tecnológico, que sustentou a constituição do modernismo brasileiro na Arquitetura uma reflexão teórica, associada a práticas experimentais, que organiza e consolida uma linha de pensamento, que correlaciona projeto social e projeto de arquitetura/ de espaço.

É esse o desafio que se recoloca. D iferentemente daquele momento, o papel da cidade e do ambiente construído é hoje muito mais importante e economicamente muito mais significativo. A importância econômica do local "qualificado" para os setores de ponta é muito maior, assim como a parcela da valorização imobiliária em relação ao ganho na produção na indústria da construção. Portanto, falar em projeto urbano éfalar em modelo de desenvolvimento - e esse é o desafio. M as essa correlação raramente é posta em evidência. É necessário, pois, desvendá-la.

\section{Avaliações finais}

Todas essas instâncias: subprefeituras, plano diretor, conselhos, mais os planos regionais, de habitação, de transportes e de uso do solo convergem na configuração do que podemos designar por construção de uma política urbana - que 
inclui leis, planos e recursos, mas que requer, principalmente, a constituição de uma forma de gestão, onde a participação da sociedade, de forma direta, não só é essencial, mas desdobramento de determinações constitucionais.

A importância da construção da política urbana baseia-se na hipótese de que a ação dos municípios, na esfera de sua específica competência, tem um imenso potencial capaz de favorecer ou restringir processos de inclusão social, promovendo ou comprometendo a modernização da sociedade brasileira e o desenvolvimento. 0 impacto da ação urbanística - regulação e intervenções no uso e ocupação do solo - também é fundamental: ao investir-se num setor já qualificado da cidade, amplia-se a diferença de qualidade em relação aos demais lugares, tornando a periferia cada vez mais periferia, cada vez mais desqualificada e distante. Entenda-se aqui periferia não apenas como o lugar geográfico, mas como defasagem dos pontos qualificados, o que evidentemente inclui as áreas deterioradas do centro da cidade.

Além disso, cumpre considerar a capacidade de gestão do poder público (no caso, o municipal). Sendo ela, num dado momento, finita e não elástica, é fundamental observar os focos de sua ação. Ao promover ou qualificar uma determinada área, está investindo nela parte desses recursos, o que significa que estará menos presente nas demais áreas. $\mathrm{E}$ aqui é bom lembrar que existe uma clara relação entre a ausência do poder público no território e a violência.

Por fim, em relação à socialização da valorização imobiliária, decorrente do investimento público e apropriado de modo privado, observa-se um desafio recorrente: cada novo instrumento procura realizar o que os anteriores não foram capazes. 0 propósito de socializar a valorização imobiliária advinda do investimento público ou da coletividade é antigo. Para esse fim, existe a contribuição de melhoria desde meados do século XX - sua aplicação, de difícil cálculo, foi raramente utilizada. O I PTU, que permite cobrança diferenciada, em função da avaliação do valor venal, também não vem conseguindo fazê-lo, seja por dificuldades técnicas quanto por estar sempre submerso mais na lógica fiscal/ arrecadatória do que urbanística. A partir do Estatuto da Cidade foi definida a outorga onerosa com esse mesmo fim. A Lei do Plano Diretor Estratégico de São Paulo a inclui entre os instrumentos que utiliza. No entanto, ao criar conjuntamente a figura das operações urbanas, tende a reduzir seu efeito, conforme mostramos anteriormente.

$\mathrm{M}$ as, em termos de qualidade urbana, garantindo a função social da cidade e da propriedade, induzindo a destinação dos imóveis para o consumo e não para reserva de valor, o mais importante dos instrumentos é a utilização compulsória e a sanção por sua não utilização. É fundamental explicitar socialmente esse objetivo. Assim como a multa tem objetivo claro de induzir comportamentos socialmente adequados (conforme presumido nas leis) - por exemplo, a proibição de circular nos horários de pico em determinado dia da semana, é assim que se justifica o imposto territorial progressivo no tempo - tem caráter de coibir, não de arrecadar. 
N otas

1 Fundação Seade. São Paulo - Guia de investimentos e de geração de empregos. São Paulo, a metrópole das economias emergentes. Página web, 16/ 3/ 2003.

2 Fundação Seade. Pesquisa emprego e desemprego na RM SP. Página web, 16/ 3/ 2003.

3 Fundação J oão Pinheiro. Informativo C.E.I. D éficit H abitacional no Brasil 2.000. Belo H orizonte, 2001.

4 Entre eles se encontra o PL no 1 de 2001, apresentado pela M esa da Câmara a partir de proposta oferecida como contribuição pelo IEA. O s estudos foram desenvolvidos por Grupo de Estudos no IEA, incluindo especialistas e professores da U SP, FGV e PU C. O uvindo entidades da sociedade civil e organismos municipais e estaduais cuja atuação ou base de representação tem referência territorial, o grupo elaborou a proposta, sob forma de projeto de lei acabado, oferecendo-o à M esa da Câmara, como produto de debate na sociedade e trabalho técnico.

5 J osé M arti, placa de bronze no Palacio de los C apitanes - Plaza de Armas, $\mathrm{H}$ avana, C uba. 6 Emplasa, página web: www.emplasa.sp.gov.br; ago. 2002.

7 A proposta de desenvolver soluções urbanísticas que sejam ambientalmente sustentáveis e passíveis de regularização jurídica para ocupações consolidadas em área de mananciais consubstanciou-se em tema de trabal ho para atividade de pesquisa, extensão e atividade didática, desenvolvida de modo conjunto entre $\mathrm{o} L$ aboratório de $\mathrm{H}$ abitação e Assentamentos H umanos da Faculdade de Arquitetura e U rbanismo da U niversidade de São Paulo e o C entro de A poio às Promotorias de $\mathrm{H}$ abitação e U rbanismo do M inistério Público do Estado de São Paulo, desde o ano de 2000. M aiores detalhes no site www.usp.br/ fau/ depprojeto/ labhab.

8 Alternativamente, e com os mesmos objetivos da ação civil, o M inistério Público pode propor um termo de ajustamento de conduta - que é um acordo, feito com o acusado ou conjunto de co-responsáveis, contendo o reconhecimento da culpa e um plano de reparação. 0 termo de ajustamento de conduta se torna um título extrajudicial, imediatamente passível de execução. Portanto, é muito mais rápido e de menores custos do que uma ação civil pública.

9 M urillo M arx, Cidadeno Brasil, terra dequem?, São Paulo, N obel, 1991.

10 Flávio Villaça, Espaço intra-urbano no Brasil, São Paulo, Studio N obel, 1998.

11 Entre essas iniciativas está o L aboratório de $\mathrm{H}$ abitação e Assentamentos $\mathrm{H}$ umanos da FAU -U SP, criado pela Profa. Ermínia M aricato em 1997, com objetivos de desenvolver fundamentação teórica e conhecimento técnico na área dos assentamentos humanos visando à formação de pesquisadores e profissionais para as políticas públicas. 0 enfoque crítico e analítico fornece uma base para a intervenção - sob a forma de projetos, programas, planos e gestão - sobre a cidade real, direcionada ao interesse público e à inclusão social.

Maria Lucia R efinetti Martins é arquiteta formada pela FAU -U SP, mestre e doutora em Planejamento U rbano e R egional também pela FAU -U SP. Professora do D epartamento de Projeto e Coordenadora do $\mathrm{L}$ aboratório de $\mathrm{H}$ abitação e Assentamentos $\mathrm{H} \mathrm{u}$ manos da Faculdade de Arquitetura eU rbanismo da U SP. Anteriormente exerceu atividade de planejador urbano na Secretaria M unicipal de Planejamento da PM SP e de assessoria em urbanismo a parlamentaresna Câmara M unicipal de São Paulo eAssembléia L egislativa. 